\title{
Inheritance of Shoulder Spotting in the Red-base Tetra (Chara- cidae: Hemigrammus stictus)
}

\author{
Jack S. Frankel* \\ Department of Biology, Howard University, Washington, DC 20059, USA
}

Received: January 26, 2011 / Accepted: May 8, 2011

\begin{abstract}
The Red-base tetra (Hemigrammus stictus) exhibits two phenotypes associated with shoulder spotting. Fish either possess a prominent black shoulder spot located directly behind the operculum or lack this spotting pattern. Segregation patterns observed from the progenies of eleven different crosses suggest that the inheritance of shoulder spotting is controlled by the action of two autosomal loci acting in a complementary recessive fashion, with dominance at either locus resulting in the expression of the spotted phenotype.
\end{abstract}

Key Words: Hemigrammus stictus, Red-base tetra, shoulder spotting, Characidae.

\footnotetext{
* Corresponding author: ifrankel@howard.edu
}

\section{Introduction}

Fishes in the teleost genus Hemigrammus (Characidae) exhibit a broad spectrum of body colorations and marking patterns (Axelrod and Vorderwinkler, 1995; Riehl et al., 1997; Frankel, 2000, 2002). The Red-base tetra ( $H$. stictus), so named due to the prominent red coloration found on both the caudal peduncle and caudal fin, is a South American characin that is easily maintained and bred in captivity. While not a commonly imported species, $H$. stictus routinely appears in catches of the more popular South American characins collected from Venezuela, Guyana, and Brazil and, as such, is usually available to aquarists. In addition to this strikingly red caudal region, both female and male fishes in natural populations of $H$. stictus characteristically exhibit a prominent black spot or patch located caudally to the operculum. While this shoulder spot is a feature of virtually all individuals of $\mathrm{H}$. stictus, a rare alternate phenotype is occasionally found which lacks this shoulder spot. The inheritance of this spotting pattern is of particular interest, since it most probably serves a prominent role in protecting individuals from predation by acting as an eye-spot. As a result of our interest in the 
Table 1. Probable genotypes (PG), observed phenotypic numbers, expected ratios, degrees of freedom (df), chi-square values ( $\left.X^{2}\right)$ and probability of fit $(\mathrm{P})$ for crosses amongst spotted and unspotted Hemigrammus stictus.

\begin{tabular}{|c|c|c|c|c|c|c|c|}
\hline \multirow{2}{*}{$\begin{array}{l}\text { Cross } \\
\text { No. }\end{array}$} & \multirow{2}{*}{$\begin{array}{lll}\text { Parents* } & & \\
\text { 이 } & \text { (PG) } & \text { (PG) }\end{array}$} & \multicolumn{2}{|c|}{ Phenotypic numbers } & \multirow[t]{2}{*}{ Exp. Ratio } & \multirow[t]{2}{*}{$d f$} & \multirow[t]{2}{*}{$x^{2}$} & \multirow[t]{2}{*}{$\mathbf{P}^{+}$} \\
\hline & & Spotting & No Spotting & & & & \\
\hline 1 & $\mathrm{SI} \quad(A A B B) \times \mathrm{S} 1(A A B B)$ & $40(F I \& F 1)$ & 0 & $1: 0$ & & & \\
\hline 2 & $\mathrm{SII}(A A B B) \times \mathrm{S} 2(A A B B)$ & 51 & 0 & $1: 0$ & & & \\
\hline 3 & SIII $(A A B B) \times$ S3 $(A A B B)$ & 50 & 0 & $1: 0$ & & & \\
\hline 4 & $\operatorname{SIV}(A A B B) \times S 4(A A B B)$ & 38 & 0 & $1: 0$ & & & \\
\hline 5 & $\mathrm{SV}(A A B B) \times \mathrm{S} 5(A A B B)$ & $42(\mathrm{FII} \& \mathrm{~F} 2)$ & 0 & $1: 0$ & & & \\
\hline \multirow[t]{2}{*}{6} & SI $(A A B B) \times S 4(A A B B)$ & 46 & 0 & $1: 0$ & & & \\
\hline & Pooled & 267 & 0 & $1: 0$ & & & \\
\hline 7 & NI $\quad(a a b b) \times N 1(a a b b)$ & 0 & $35(\mathrm{FIII} \& \mathrm{~F} 3)$ & $0: 1$ & & & \\
\hline 8 & NII $(a a b b) \times \quad N 2(a a b b)$ & 0 & 46(FIV\&F4) & $0: 1$ & & & \\
\hline \multirow[t]{2}{*}{9} & NIII $(a a b b) \times \quad N 3(a a b b)$ & 0 & 47 (FV\&F5) & $0: 1$ & & & \\
\hline & Pooled & 0 & 128 & $0: 1$ & & & \\
\hline 10 & SI $\quad(A A B B) \times$ Fl $(A A B B)$ & 32 & 0 & $1: 0$ & & & \\
\hline 11 & $\mathrm{FI} \quad(A A B B) \times$ SI $(A A B B)$ & 30 & 0 & $1: 0$ & & & \\
\hline 12 & $\mathrm{SV}(A A B B) \times \mathrm{F} 2(A A B B)$ & 41 & 0 & $1: 0$ & & & \\
\hline \multirow[t]{2}{*}{13} & FII $(A A B B) \times S 5(A A B B)$ & 44 & 0 & $1: 0$ & & & \\
\hline & Pooled & 147 & 0 & $1: 0$ & & & \\
\hline 14 & NI $(a a b b) \times F 3(a a b b)$ & 0 & 43 & $0: 1$ & & & \\
\hline 15 & NII $(a a b b) \times$ F4 $(a a b b)$ & 0 & 29 & $0: 1$ & & & \\
\hline 16 & NIII (aabb) x F5 (aabb) & 0 & 47 & $0: 1$ & & & \\
\hline 17 & $\operatorname{FIV}(a a b b) \times N 2(a a b b)$ & 0 & 33 & $0: 1$ & & & \\
\hline \multirow[t]{2}{*}{18} & $\mathrm{FV}(a a b b) \times N 3(a a b b)$ & 0 & 35 & $0: 1$ & & & \\
\hline & Pooled & 0 & 187 & $0: 1$ & & & \\
\hline 19 & SI $(A A B B) \times N 1(a a b b)$ & $37(\mathrm{FVI} \& \mathrm{~F} 6)$ & 0 & $1: 0$ & & & \\
\hline 20 & SII $(A A B B) \times N 2(a a b b)$ & 32 (FVII\&F7) & 0 & $1: 0$ & & & \\
\hline 21 & $\operatorname{SIII}(A A B B) \times N 3 \quad(a a b b)$ & $44(\mathrm{FVIII} \& \mathrm{~F} 8)$ & 3) 0 & $1: 0$ & & & \\
\hline 22 & N1 $(a a b b) \times S 4 \quad(A A B B)$ & 31 (FIX\&F9) & 0 & $1: 0$ & & & \\
\hline \multirow[t]{2}{*}{23} & NII (aabb) x S5 (AABB) & $35(F X \& F 10)$ & ) 0 & $1: 0$ & & & \\
\hline & Pooled & 179 & 0 & & & & \\
\hline 24 & $\mathrm{FVI} \quad(A a B b) \times \mathrm{F} 6(A a B b)$ & 38 & 2 & $15: 1$ & 1 & .107 & .7440 \\
\hline 25 & FVII $(A a B b) \times F 7(A a B b)$ & 37 & 5 & $15: 1$ & 1 & 2.292 & .1300 \\
\hline 26 & FVIII $(A a B b) \times F 8(A a B b)$ & 48 & 3 & $15: 1$ & 1 & .012 & .9136 \\
\hline 27 & $\mathrm{FIX} \quad(A a B b) \times \mathrm{F} 9(A a B b)$ & 37 & 1 & $15: 1$ & 1 & .849 & .3568 \\
\hline 28 & $\mathrm{FX} \quad(A a B b) \times \mathrm{FX}(A a B b)$ & 33 & 4 & $15: 1$ & 1 & 1.314 & .2518 \\
\hline 29 & $\mathrm{FVI} \quad(A a B b) \times \mathrm{F} 8(A a B b)$ & 28 & 1 & $15: 1$ & 1 & .389 & .5331 \\
\hline \multirow[t]{3}{*}{30} & FVII $(A a B b) \times$ F9 $(A a B b)$ & 60 & 6 & $15: 1$ & 1 & .909 & .3404 \\
\hline & $\begin{array}{l}\text { Total } \\
\text { Pooled }\end{array}$ & 281 & 22 & $15: 1$ & $\begin{array}{l}7 \\
1\end{array}$ & $\begin{array}{l}5.872 \\
.528\end{array}$ & $\begin{array}{l}.5547 \\
.4673\end{array}$ \\
\hline & Heterogeneity & & & & 6 & 5.344 & .5005 \\
\hline 31 & FIX $\quad(A a B b) \times F 3(a a b b)$ & 28 & 8 & $3: 1$ & 1 & .148 & .7003 \\
\hline 32 & $\mathrm{FX} \quad(A a B b) \times \mathrm{F} 4(a a b b)$ & 35 & 10 & $3: 1$ & 1 & .185 & .6670 \\
\hline 33 & FIV $(a a b b) \times$ F8 $(A a B b)$ & 30 & 9 & $3: 1$ & 1 & .077 & .7815 \\
\hline \multirow[t]{4}{*}{34} & FV $\quad(a a b b) \times$ F9 $(A a B b)$ & 15 & 7 & $3: 1$ & 1 & .545 & .4602 \\
\hline & Total & & & & 4 & .955 & .9165 \\
\hline & Pooled & 108 & 34 & $3: 1$ & 1 & .085 & .7713 \\
\hline & Heterogeneity & & & & 3 & .870 & .8326 \\
\hline
\end{tabular}

$*(S)=$ spotted parental fishes; $(N)=$ unspotted parental fishes; $(F)=F 1$ offspring. + The probability for all X2 tests is $>.05$; thus, all observed results fit the expected ratio according to Mendelian inheritance. 
inheritance of disruptive banding and spotting patterns in several genera of freshwater teleosts (Frankel, 1985, 1991, 1998, $2001,2002,2004,2005,2009$ ), the present study was undertaken to ascertain the mode of inheritance of shoulder spotting in $H$. stictus.

\section{Materials and Methods}

Healthy juvenile specimens of $H$. stictus were obtained from a wholesale distributor in Maryland, USA, and maintained in separate 76 liter holding tanks at $26^{\circ} \mathrm{C}$. Male and female fishes exhibiting either the characteristic shoulder spotting phenotype or the unspotted phenotype, were selected at random from stock specimens, placed in separate 76 liter tanks, and allowed to develop at $26^{\circ} \mathrm{C}$ until sexually mature. Optimal water conditions for Hemigrammus were provided for all fish (i.e. low water hardness of $5^{\circ} \mathrm{dGH}, \mathrm{pH} 6.5$, and temperature $26^{\circ} \mathrm{C}$ ) (Riehl et al., 1997). All progeny for this study were obtained from artificial fertilizations as previously described (Frankel, 1985). Parental fishes, exhibiting either the spotted (S) or unspotted (N) phenotype, along with $\mathrm{Fl}$ progeny $(\mathrm{F})$, were used in a series of 34 crosses (Table 1). Embryos from all crosses were incubated at $26^{\circ} \mathrm{C}$ in $250 \mathrm{ml}$ fingerbowls containing tank water. Dead or developmentally arrested embryos were removed daily. Fry hatched 24-36 hours post-fertilization and were free-swimming 72-96 hours post-hatching. Progeny groups were placed in separate 36 liter rearing tanks, fed initially on rotifers and allowed to develop until their phenotype could be visually determined. Since spotting is more defined in mature individuals, determination of spotting was only scored for mature individuals. Phenotypic data of all progeny were recorded and subjected to chi-square analysis. Pooled and heterogeneity chi-square tests were also performed, treating the progenies from reciprocal $\mathrm{Fl} \times \mathrm{Fl}$ crosses as single large progenies in an analysis of overall goodness of fit.

\section{Results and Discussion}

Table 1 presents data for the proposed genotypes of parental fishes, observed phenotypic numbers, expected ratios, and probability of fit for $\mathrm{H}$. stictus analyzed for the mode of inheritance of shoulder spotting. Parental fishes and progeny from all crosses clearly displayed either the spotted or unspotted phenotype. Spotted females SI, SII, SIII, SIV, SV and males S1, S2, S3, S4, S5 were scored as homozygous dominants, as crosses involving these individuals always resulted in spotted progeny (crosses 1-6, 10-13, 19-23). Parental fishes lacking shoulder spots (NI, NII, NIII, females and N1, N2, N3 males) were scored as homozygous recessives, as crosses amongst these individuals consistently bred true (crosses 7-9). Further, when FIV and and FV females, and F3, F4, and males were crossed with their parents, the resulting offspring consistently lacked a shoulder spot (crosses 14-18). In addition, reciprocal crosses between spotted and unspotted parental fishes always resulted in spotted progeny (crosses 19-23).

Crosses amongst the $\mathrm{Fl}$ fishes resulting from parental matings always resulted in a satisfactory fit to a 15:1 phenotypic ratio of F2 progeny (crosses 24-30), commensurate with a modified 9:3:3:1 ratio resulting from recessive complementary gene action; the aabb genotype resulting in fishes absent shoulder spotting. This mode of inheritance was further substantiated by matings between presumptive $\mathrm{Fl}$ homozygous recessives and $\mathrm{Fl}$ heterozygotes (crosses 31-34). Both spotted and unspotted fry resulted from these matings and, based on chi-square analyses, conformed to the expected 3:1 phenotypic ratio.

Results of this study support the hypothesis that shoulder spotting in $\mathrm{H}$. stictus is controlled by two loci acting in a complementary fashion, with dominance at either locus required for the expression of the spotted phenotype. Segregation patterns for the spotted and unspotted phenotypes of $H$. stictus clearly fit an autosomal pattern of inheritance, as chi-square tests do not deviate significantly from expectations. Results of heterogeneity tests also support the acceptance of the null hypothesis for this data. Further, observations of the extent of spotting in parental, $\mathrm{Fl}$, and $\mathrm{F} 2$ fishes also suggest that these loci do not act in an additive fashion, since there is no perceptible difference in the appearance of spotting in presumptive $A A B B$ spotted parentals $(S)$ with either presumptive $A a B b$ spotted F1 progeny (FVI-FX and F6-F10) or spotted F2 fishes, some of which would be heterozygous at one of the two loci involved (i.e. Aabb or $a \mathrm{aBb}$ individuals).

A digenic mode of inheritance has also been reported for shoulder spotting in the tetra Hyphessobrycon bentosi Characidae (Frankel, 2009), although in this species shoulder spotting results from a pair of autosomal loci exhibiting dominant complementary gene action. As in $H$. bentosi, the prominent dark shoulder spot in the Red-base tetra most certainly serves as an "eye-spot" and, therefore, gives a selective advantage to those individuals possessing this feature by providing them with an interspecific marking to minimize predation. Indeed, the mode of inheritance suggested here for shoulder spotting in $\mathrm{H}$. stictus would clearly provide for individuals in populations of this species to exhibit the spotted phenotype (i.e. A_bb, aaB_, and A_B_all result in the expression of shoulder spotting). Interestingly, spotting is not always the preferred or prominent phenotypic alternative in fishes. For instance, studies on the mosquitofish (Gambusia holbrooki) (Bisazza and Pilastro, 2000; Horth, 2006), have shown that the melanic (mottled-black) body spotting pattern is inherited as a Y-linked trait with autosomal modifiers and is either expressed in very low frequency or is completely absent from certain populations of this poeciliid.

\section{References}

Axelrod HR, and W Vorderwinkler (1995) Encyclopedia of tropical fishes with special emphasis on techniques of breeding. TFH Publications. pp. 174-184.

Bisazza A, and A Pilastro (2000) Variation of female preference for male coloration in the eastern mosquitofish (Gambusia holbrooki). Behavior Genet 30: 207-212.

Frankel JS (1985) Inheritance of trunk striping in the Sumatran tiger barb, Barbus tetrazona. J Hered 76: 478-479.

Frankel JS (1991) Inheritance of body marking patterns in the half-banded barb, Barbus semifasciolatus. J Hered 82: 250-251.

Frankel JS (1998) Monogenic inheritance of trunk banding patterns in the Sumatra barb, Barbus tetrazona. J Fish Biol 53: 1357-1359. 
Frankel JS (2000) Monogenic control of iris coloration in the January tetra (Hemigrammus hyanuary Characidae). J Hered 91: 411-412.

Frankel JS (2001) Inheritance of caudal peduncle banding in the spiketailed paradisefish. J Fish Biol 59: 1095-1097.

Frankel JS (2002) Caudal spotting in the beacon fish (Hemigrammus ocellifer Characidae). J Hered 93: 285-286.

Frankel JS (2004) Inheritance of trunk banding in the tetra (Gymnocorymbus ternetzi Characidae). J Hered 95: 262-264.

Frankel JS (2005) Digenic control of colouration in the two-spot goura- mi, Trichogaster trichopterus trichopterus. J Genet 84: 101-103.

Frankel JS (2009) Inheritance of shoulder spotting in the tetra, Hyphessobrycon bentosi Characidae. Open Fish Sci J 2: 39-41

Horth L (2006) A sex-linked allele, autosomal modifiers and temperature-dependence appear to regulate melanism in male mosquitofish (Gambusia holbrooki). J Exp Biol 209: 4938-4945.

Riehl R, H Baensch, H Smith, E Schulze, and B Behme (1997) Baensch aquarium atlas: $6^{\text {th }}$ ed. Steven Simpson Books. pp. 266-280. 